\title{
Adaptation to statins restricts human tumour growth in Nude mice
}

\author{
Julie Follet ${ }^{1}$, Lionel Rémy ${ }^{2}$, Vincent Hesry ${ }^{3}$, Brigitte Simon ${ }^{1}$, Danièle Gillet ${ }^{1}$, Pierrick Auvray ${ }^{3}$, Laurent $\operatorname{Corcos}^{1}$ and \\ Catherine Le Jossic-Corcos ${ }^{1 *}$
}

\begin{abstract}
Background: Statins have long been used as anti-hypercholesterolemia drugs, but numerous lines of evidence suggest that they may also bear anti-tumour potential. We have recently demonstrated that it was possible to isolate cancer cells adapted to growth in the continuous presence of lovastatin. These cells grew more slowly than the statin-sensitive cells of origin. In the present study, we compared the ability of both statin-sensitive and statinresistant cells to give rise to tumours in Nude mice.

Methods: HGT-1 human gastric cancer cells and L50 statin-resistant derivatives were injected subcutaneously into Nude mice and tumour growth was recorded. At the end of the experiment, tumours were recovered and marker proteins were analyzed by western blotting, RT-PCR and immunohistochemistry.

Results: L50 tumours grew more slowly, showed a strong decrease in cyclin B1, over-expressed collagen IV, and had reduced laminin 332, VEGF and CD34 levels, which, collectively, may have restricted cell division, cell adhesion and neoangiogenesis.

Conclusions: Taken together, these results showed that statin-resistant cells developed into smaller tumours than statin-sensitive cells. This may be reflective of the cancer restricting activity of statins in humans, as suggested from several retrospective studies with subjects undergoing statin therapy for several years.
\end{abstract}

Keywords: Statins, Gastric cancer, Nude mice, Apoptosis, Angiogenesis

\section{Background}

Statins are widely used anti-hypercholesterolemia drugs and act through competitive inhibition of HMG-CoA reductase, the first enzyme controlling entry into the mevalonate pathway that leads, ultimately, to cholesterol and steroid hormone synthesis [1]. This drug family comprises both natural (lovastatin, simvastatin, pravastatin) and synthetic (fluvastatin, atorvastatin) molecules that efficiently lower LDL cholesterol levels [2]. Apart from their role in the control of cholesterol homeostasis, statins have been proposed to lower cancer incidence in several large trials, for colon, breast and lung cancers, among others [3,4]. However, other large trials have not confirmed this potential chemo-preventive effect [5].

\footnotetext{
* Correspondence: catherine.corcos@univ-brest.fr

'INSERM U613-ECLA and IFR148-ScInBioS, Université Européenne de Bretagne, Université de Bretagne Occidentale, Faculté de médecine, 22 avenue Camille Desmoulins, 29200 Brest, France

Full list of author information is available at the end of the article
}

The origin of the differences is not known, but a recent study indicated that these might partly depend on the particular allelic form of the HMGCR gene (encoding HMG-CoA reductase), as an alternative pre-mRNA splicing event - associated with a specific SNP genotype leads to differences in the activity of the enzyme [6].

In addition to this cancer prevention potential, statins have long been known to trigger apoptosis in many cell culture models, to prevent or reduce tumour occurrence in animals or to reduce the incidence of metastases [7]. The tumour suppressive effect has been proposed to rely partly on the ability of statins to block production of farnesyl pyrophosphate or geranyl-geranyl pyrophosphate, which provide target proteins with $\mathrm{C} 15$ or C20 post-translational carbon chain additions that help signalling molecules like Ras or Rho anchor to the plasma membrane and drive cell proliferation [8,9]. Cholesterol deprivation might also hamper tumour cell proliferation by restricting the ability to renew membrane pools. 
Other effects, linked to reduced respiration potential, have also been proposed [10].

One question that arises is what would happen, in the apoptotic response, if the sensitivity of the cells to statins was reduced, either as an intrinsic or an acquired phenotype following long periods of drug intake? To address this question, we isolated a population of statinresistant cells, which we named L50, that was stably resistant to a relatively high concentration of statins in culture $(50 \mu \mathrm{M})$, derived from the human gastric cancer HGT-1 cell line [11]. These cells showed increased expression of pro-caspase-7, that we further showed to be under the positive control of SREBP-1 and SREBP-2 proteins, much like proteins from the mevalonate pathway and pro-caspase-2 [12]. In vitro growth of HGT-1 and L50 cells showed that the latter had a reduced growth rate, suggesting that, should intrinsic resistance to statins occur, it would not be associated with increased growth. The aim of the present study was to investigate cell growth parameters and marker gene expression in tumours developed in Nude mice from HGT-1 or L50 cells.

Our results showed that tumour growth was slower in L50 than in HGT-1 tumours, as found for cells grown in vitro. In addition, the over-expression of caspase-7 in L50 vs HGT-1 cells was maintained in tumours, further demonstrating phenotype stability. The lower growth of L50 tumours was associated with a strong reduction in cyclin B1. In addition, these L50 tumours showed overexpression of collagen IV, and reduced laminin 332, VEGF and CD34 levels, which may have restricted cell adhesion and neoangiogenesis. Taken together, these results suggest that adaptation to statins led to important phenotype modifications, which, collectively, conferred a reduced ability of tumour cells to grow in immuno-compromised mice.

\section{Methods}

\section{Cell culture}

HGT-1 human gastric cancer cells and HGT-1-derived L50 cells were grown at $37^{\circ} \mathrm{C}$ under a humidified atmosphere of $5 \% \mathrm{CO}_{2}$ in DMEM (Dulbecco's modified Eagle's medium) (Lonza, Saint Beauzire, France), containing 4.5 g.L $\mathrm{L}^{-1}$ glucose and supplemented with $5 \%$ $(\mathrm{v} / \mathrm{v})$ foetal bovine serum without antibiotics (GibcoInvitrogen, Cergy Pontoise, France) [11,13]. L50 cells had been selected following several weeks of permanent growth in presence of $50 \mu \mathrm{M}$ lovastatin. Cell death no longer occurred after that period and phenotype stability was ascertained over several cell passages in the absence of lovastatin [11]. HGT-1 and L50 cells were grown and used for injection into Nude mice (see below).

\section{Tumour induction in Nude mice}

Twenty healthy female Balb/c Nude mice (4 weeks-old) were obtained from Charles River (L'Arbresle, France). Animals were maintained for 7 days in a conventional animal care unit before the start of the study (INSERM U625, Rennes, France, Agreement No. 4016 from the French Ministries of Agriculture and Research). Animal experiments were performed according to ethical guidelines of animal experimentations.

Before cell injection, the mice were anesthetised by intra-peritoneal injection of pentobarbital $(70 \mathrm{mg} / \mathrm{kg}$; Sigma, France). The cells $\left(2 \times 10^{7}\right.$ cells/mouse in $200 \mu \mathrm{l}$ of serum-free medium) were then inoculated by subcutaneous injection in the right flank of each mouse (10 mice per group). After cell inoculation, mice were observed for $2 \mathrm{~h}$ post-injection to ascertain that no health condition occurred. Tumour growth was followed during 31 days. The tumor volume was calculated according to the formula: (length $\times$ width $^{2}$ )/2 [14]. Randomization all along the covered period, including randomization to affect animals to the treatment groups, to pick up the mice from both groups and to measure the tumour volumes was used for all the experiment. At the end of this period, the mice were sacrificed and tumours were recovered for analysis.

\section{Protein extraction and western blotting analysis}

Frozen tumours were rapidly homogenised in Phosphate Buffered Saline (PBS) and lysed in ripa buffer (50 mM Tris $\mathrm{HCl}$ pH7.4, $150 \mathrm{mM} \mathrm{NaCl}, 0.5 \%$ (wt/v) Sodium deoxycholate, 0.1\% SDS, 1\% NP40, $1 \mathrm{mM}$ EDTA, $1 \mathrm{mM}$ PMSF) containing protease inhibitor cocktail (Roche, Meylan, France) and phosphatase inhibitor (Active motif) for $10 \mathrm{~min}$ at $4^{\circ} \mathrm{C}$. Sixty micrograms of proteins were boiled in Laemmli buffer for $5 \mathrm{~min}$, separated by SDS-PAGE using $12 \%$ or $15 \%$ polyacrylamide gels and blotted onto polyvinyl difluoride membranes (GE Healthcare). Non specific binding sites were blocked for $1 \mathrm{~h}$ at room temperature by $5 \%(\mathrm{wt} / \mathrm{v})$ fat-free milk before an overnight incubation at $4^{\circ} \mathrm{C}$ with specific rabbit anti-human antibodies: procaspase-3, $-6,-7$ or -9 , aurora kinase A and B, Bcl-2, Bax and survivin (Cell Signalling Technology-Ozyme, Saint Quentin en Yvelines, France), p21, Mcl-1 and cyclin B1 (Santa Cruz biotechnology, Tebu-bio, le Perray en Yvelines, France), cyclin D1 (NeoMarkers, Thermo Fisher Scientific, Illkirch, France) or HSC70 (Abcam, Paris, France) as a loading control. Primary antibodies were detected with a horseradish peroxidase-conjugated donkey anti-rabbit IgGs (GE Healthcare, Orsay, France). Blots were revealed using an Enhanced Chemiluminescence detection kit (GE Healthcare) and analyzed with the Chemcapt ${ }^{\mathrm{TM}}$ software. 


\section{Immunofluorescence analysis}

In situ analyses of structural proteins were performed as previously reported [15]. Antibodies sources were as follows: laminins 332 and 111 (gifts of Dr Patricia Rousselle, CNRS, Lyon), E-Cadherin (Zymed, USA), CD34 (Becton-Dickinson, USA), EGFR/c-erbB-2 (Zymed, USA), MMP7 (Chemicon International Inc. USA), collagen IV (Chemicon International Inc. USA).

Fixed frozen $7 \mathrm{~mm}$ tissue sections were rehydrated with $10 \%$ Fetal Calf Serum/PBS for 10 min. After several PBS washes, sections were incubated for $60 \mathrm{~min}$. with the specific antibodies, washed in PBS and incubated for 30 min. with TRITC- or FITC-conjugated secondary antibodies. After two PBS washes, sections were mounted with fluorescent mounting medium (DAKO) and analyzed with a Nikon Eclips 80i fluorescence microscope. Slides were analyzed following randomization. The labelling analysis was performed blindly, and the tissue sections (serial sections) were exposed blindly to the antibodies and read by two independent observers with at least 20 microscopic fields per condition.

\section{RNA extraction and RT-PCR analysis}

Total RNA was isolated using Trizol (Invitrogen, CergyPontoise, France) and the RNA samples were used for the first-strand cDNA synthesis with the High Capacity cDNA Reverse Transcription kit and random hexamer primers (Applied biosystems). Quantitative real-time RT-PCR was performed using the Power SYBR Green Kit (Applied biosystems) according to the manufacturer's instructions. mRNA levels were analyzed in duplicate and normalized to GAPDH mRNA as an internal control. The primer sequences and reaction conditions will be provided upon request.

\section{Results and discussion}

\section{1-Statin-resistant cells grow more slowly in Nude mice}

We have previously shown that L50 cells had a slower growth rate in vitro than HGT-1 cells [11]. To determine if this was also the case in vivo, we injected Nude mice with either cell population and analysed tumour volumes up to 31 days post-implantation. As can be seen from Figure 1, HGT-1 tumours were readily detected after 13 days, whereas it required several more days for L50 tumours to become detectable. The slope of the growth curve was lower all along for L50 cells. At the end of the growth period, the mean tumour volume was 2.5 times higher for HGT-1 than for L50, with an average doubling time of $21.7 \pm 5.12$ days for HGT-1 cells and $25.30 \pm 9.38$ days for L50 cells. This difference in growth rates was statistically significant $(P<0.05)$. These results demonstrate that statin-adapted cells had a slower growth rate in vivo, as they did in vitro. Nevertheless, the ability to form tumours was not impaired in
L50 cells since as many mice (10 animals per group) developed tumours for both cell populations.

Expression of lipid metabolism and transport genes was reduced in L50 tumours, except for SREBP-2 that was expressed at similar levels in both tumour types (Table 1).

\section{2-Marker expression in HGT-1 and L50 tumours}

To look for potential differences in marker proteins between HGT-1 and L50 tumours, we conducted a western blotting analysis. As shown in Figure 2a, pro-caspase- 3 and pro-caspase- 7 protein levels were higher in L50 tumours, albeit only slightly for pro-caspase 3, as had been seen in L50 cells in culture [11]. Similarly, a 3.9-fold and 1.5-fold over-expression of caspase-7 and caspase-3 mRNA levels, respectively, were also observed (Table 1). Pro-caspase-6 and procaspase- 9 proteins were roughly unchanged (Figure 2a). Caspase-9 mRNA level showed no change, and caspase 6 mRNA was only marginally increased (Table 1 ). Both Bax and $\mathrm{Bcl}-2$ protein levels were slightly raised in L50 tumours (Figure 2b), whereas Bcl-2 expression was really difficult to detect in HGT-1 and L50 cells in culture, suggesting that the reactivation of this gene was essential to allow both types of cells to develop into tumours. Bax and Bcl-2 mRNA were raised in L50 tumours (Table 1). Interestingly, increased expression of these two proteins has been shown in human gastric cancer samples [17]. In addition, an over-expression of $\mathrm{Bcl}-2$ has been detected in low grade and early stage of gastric carcinomas [18].

The anti-apoptotic form of Mcl-1 was strongly raised in L50 tumours. Because L50 cells grown in vitro also showed higher levels of the Mcl-1 protein (data not shown), this can be interpreted as an anti-apoptotic adaptive response to growth in the continuous presence of statins during the in vitro selection procedure, a trait that was maintained in vivo. Although a high level of Mcl-1 expression was associated with a poor prognosis for many cancer types [19], its over-expression in L50 tumours might not be relevant with respect to growth potential, which clearly is a distinct endpoint from the survival of individuals who have gone through rounds of anticancer therapies. Mcl-1 mRNA levels were not raised in L50 cells (Table 1), indicating a possible stabilization event for the protein. Survivin levels were very low and comparable between both tumour types.

We next looked at the expression of proteins involved in the control of cell division. As can be seen in Figure 2c, the levels of cyclin D1, p21 and aurora kinases A \& B proteins were not different between HGT-1 and L50 tumours. Strikingly, however, L50 tumours showed a strong decrease in the level of cyclin B1, as compared to HGT-1 tumours. In fact, over-expression of cyclin B1 has been positively correlated to grade, higher 


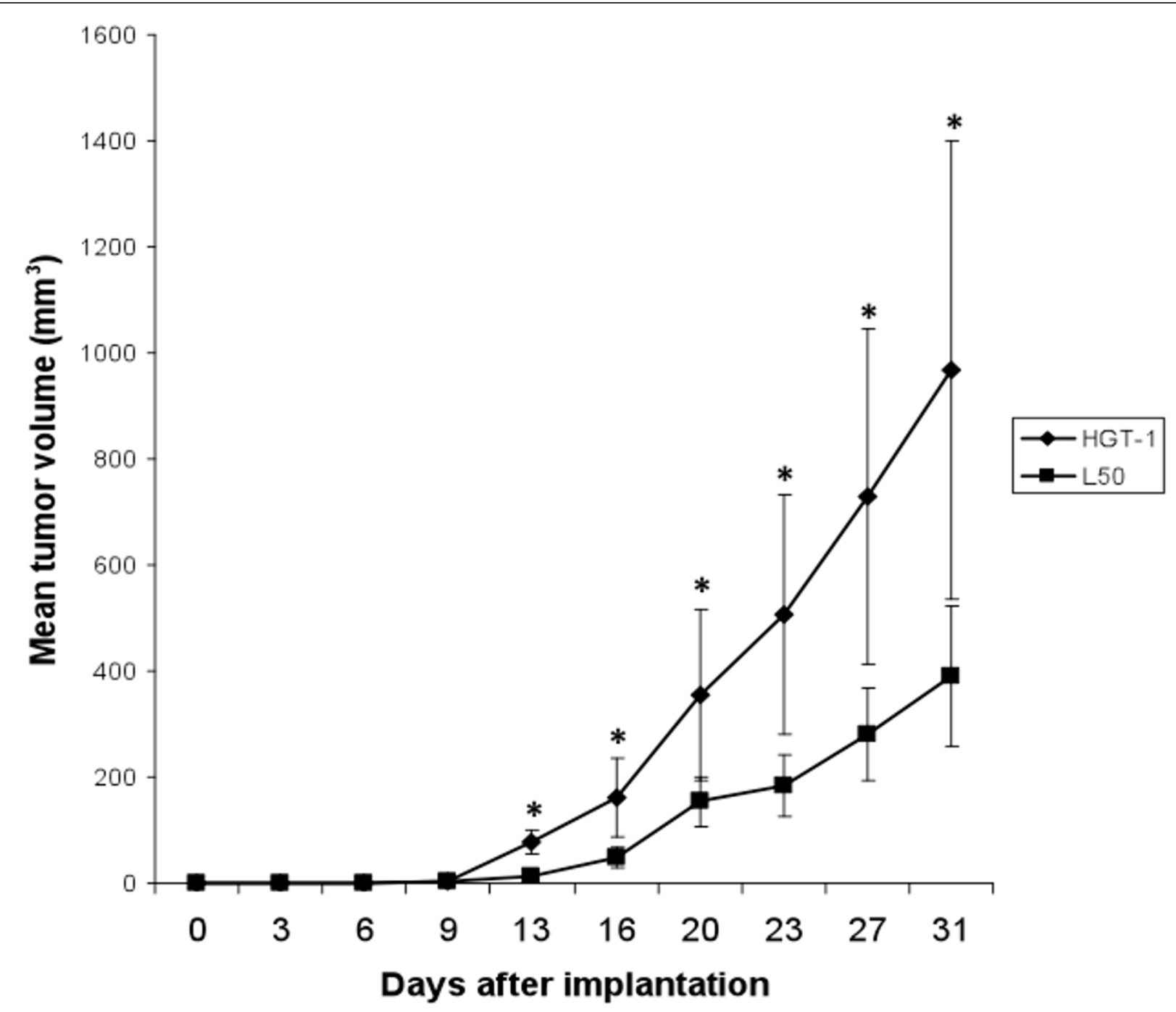

Figure 1 Tumour induction in Nude mice. HGT-1 or L50 cells were injected (subcutaneously) to Nude mice and tumour volumes were recorded as a function of time post-implantation (see Methods). Values are means \pm S.D. $(n=10)$. ${ }^{*}$ Statistical significance was set at the level of $5 \%$ (Student's $t$ test).

proliferative index, lymph node metastasis development, and invasiveness in breast, prostate and thyroid malignant lesions [20-22]. Consequently, the reduction of cyclin B1 in L50 cells might have conferred the cells a restricted proliferation potential. Cyclin B1 mRNA level was also decreased (Table 1).

Taken together, these results indicate that the slower growth of L50 tumours, as compared to HGT-1 tumours, may be attributed to a reduced activity of cell division, possibly under the control of cyclin B1.

\section{3-In situ marker analysis}

To analyse the relationship between tumour growth and the tumour environment, we next looked at the expression of extracellular matrix proteins, cellular junctions and neoangiogenesis markers by immunohistochemistry on serial sections prepared from HGT-1 and L50 tumours.

Morphology analysis showed that HGT-1 tumours were less differentiated than L50 cells, which also appeared more rounded. In addition, L50 tumours showed a lobular structure, which was not observed in HGT-1 tumours (Figure 3).

The extracellular matrix protein laminin 332 was less expressed in L50 than in HGT-1 tumours, whereas the reverse was true for collagen IV (Table 2). All the tumours expressed Laminin 332, but its localization was variable between tumour types: it was localized between the vessels of HGT-1 tumours and in the cell cytoplasm and intercellular spaces in L50 tumours, but at rather 
Table 1 RT-PCR analysis of marker gene expression in L50 tumour samples compared to HGT-1 tumours

\begin{tabular}{|c|c|c|}
\hline \multirow[t]{5}{*}{ Lipids synthesis } & HMG-CoA reductase & $0.7 \pm 0.1^{*}$ \\
\hline & SREBP-1 & $0.6 \pm 0.2^{*}$ \\
\hline & SREBP-2 & n.c. \\
\hline & LDL receptor & $0.3 \pm 0.06^{* * *}$ \\
\hline & FAS & $0.6 \pm 0.1^{* *}$ \\
\hline \multirow[t]{4}{*}{ Cell proliferation } & Cyclin D1 & $0.7 \pm 0.2^{* * *}$ \\
\hline & Cyclin B1 & $0.66 \pm 0.3^{*}$ \\
\hline & $\underline{P} 21$ & n.c. \\
\hline & EGFR & n.c. \\
\hline \multirow[t]{8}{*}{ Apoptosis } & Caspase 2 & n.c. \\
\hline & Caspase 3 & $1.5 \pm 0.4^{* *}$ \\
\hline & Caspase 6 & $1.3 \pm 0.2^{* *}$ \\
\hline & Caspase 7 & $3.9 \pm 0.6^{* * *}$ \\
\hline & Caspase 9 & n.c. \\
\hline & Bax & $1.3 \pm 0.3^{*}$ \\
\hline & $\mathrm{BCl} 2$ & $1.6 \pm 0.4^{* *}$ \\
\hline & Mcl-1 & n.c. \\
\hline
\end{tabular}

Real Time RT-PCR was performed with mRNA samples extracted from 10 tumours from independent mice. The fold variation was determined with the $\Delta \Delta$ Ct method [16]. HGT-1 mRNA levels were set to 1. The mRNA levels in L50 tumours were expressed relative to those in HGT-1 tumours. * Statistical difference $(p<0.05) ;{ }^{* *}$ Statistical difference $(p<0.01) ;{ }^{* * *}$ Statistical difference $(p<0.001)$ (Student's $t$ test) n.c. no change

low levels. Laminin 111 was strongly expressed, and at similar levels in both tumours. Nevertheless, since laminin 111 is never produced by epithelial cells, we may speculate that the observed laminin 111 staining could have been contributed by other cells. Collagen IV staining was more marked in L50 than in HGT-1 tumours (Table 2), namely at the level of blood vessels. In addition, a few cells, probably fibroblasts, expressed collagen IV in the conjunctive tissue space.

E-cadherin, an epithelial and endothelial cell junction marker, which abnormal expression has been implicated in hereditary forms of gastric cancer [23], did not display obvious differences between HGT-1 and L50 tumours, but was well expressed by the host vessels.

The neoangiogenesis CD34 marker appeared more expressed by HGT-1 tumours (Table 2), which supports the notion that angiogenesis was more active in HGT-1 than L50 tumours and, presumably, could have contributed to the higher growth rate of HGT-1 tumours when compared with L50 tumours. In addition, VEGF was strongly expressed in HGT-1 tumours but was barely detectable in L50 tumours (Figure 3 \& Table 2).

c-erbB-2, a receptor tyrosine kinase member of the EGFR family, involved in growth control, cell adhesion, migration and differentiation, was obviously expressed by stromal cells between tumour islets. In addition, L50 tumours appeared to express more c-erbB-2 than HGT1 tumours (Table 2).

Matrilysin 1 (MMP7), which is generally strongly involved in the proteolytic process of the stroma, appeared more expressed by L50 than by HGT-1 tumours at the cell level. This may seem contradictory, as the consequence of such over-expression should be increased metastatic potential for L50 cells. Nevertheless, we obtained no evidence for metastases in the course of this study. It may be possible that the threshold level for tumour cells to evade from the tumour and form metastases was not attained.

To summarize, when compared to HGT-1 tumours, L50 tumours displayed over-expression of collagen IV, c-erbB-2 and MMP7, and reduced laminin 332, CD34

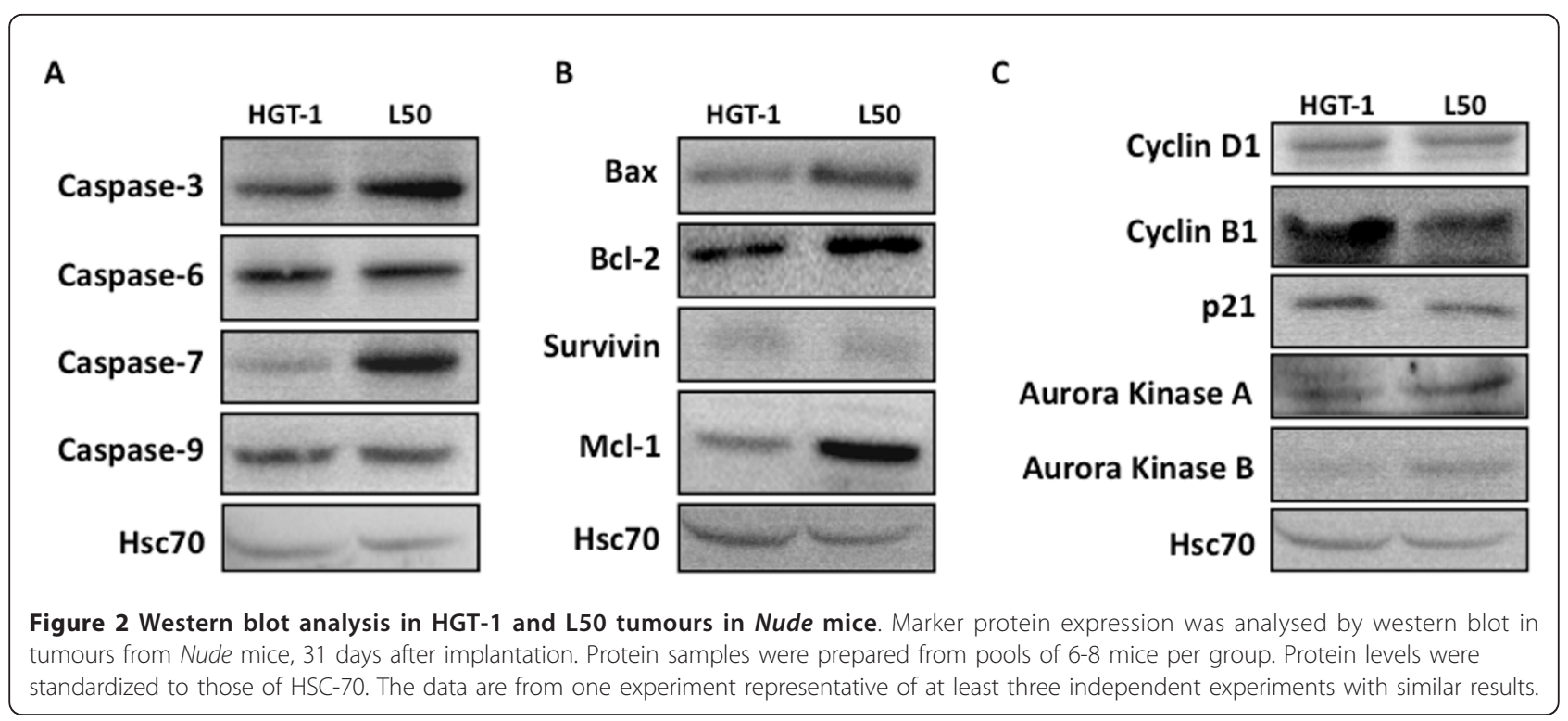


HGT-1
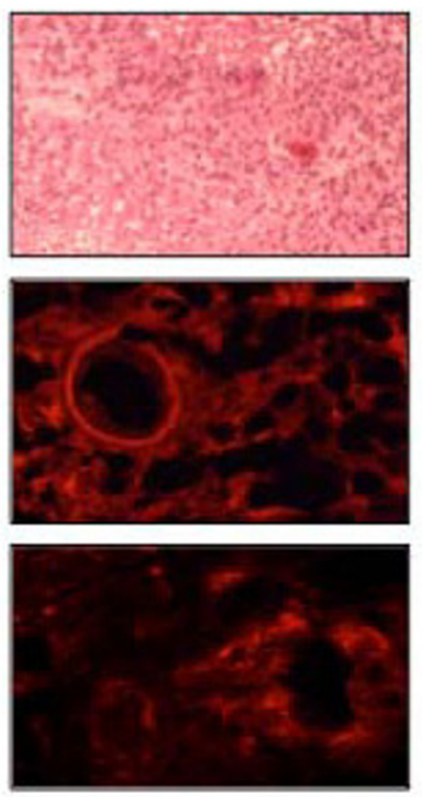

L50

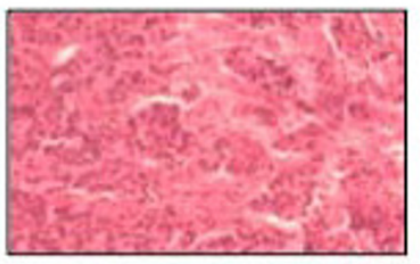

\section{Histology}

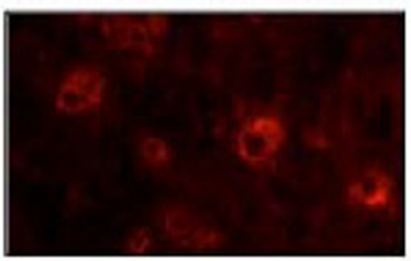

\section{Laminin 332}

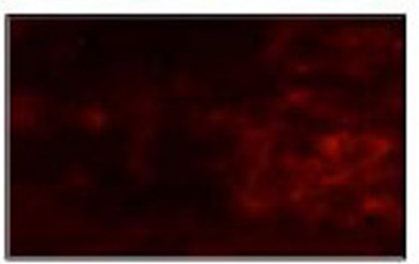

Figure 3 Histology of HGT-1 and L50 tumours. Upper panel: Representative section of HGT-1 and L50 tumours stained with hematoxylineosin (Original magnification × 200). Middle and lower panels: Immunofluorescence of HGT-1 and L50 tumours. Laminin 332 appeared more extensively expressed in HGT-1 tumours than in L50 tumours, namely in extracellular conjunctive spaces and also in some conjunctive cells. VEGF was well expressed in inter-tumoral spaces at the fiber and cell level. Its expression appeared stronger in HGT-1 than in L50 tumours (Original magnification $\times 400$ )

and VEGF levels. These results indicate that the restriction in L50 tumour growth may be largely explained by a more differentiated phenotype, and a reduced ability to undergo tumour neo-angiogenesis. Hence, it can be hypothesized that gastric cancers developed in individuals with a long history of statin treatment, might be more responsive to targeted chemotherapy including trastuzumab or lapatinib, c-erbB-2 inhibitors, which

Table 2 Semi-quantitation of protein levels from the immunofluorescence analysis

\begin{tabular}{lll}
\hline & HGT1 & L50 \\
\hline Laminin 332 & ++ & + \\
\hline Laminin 111 & ++ & ++ \\
\hline Collagen IV & + & ++ \\
\hline E-Cadherin & + & + \\
\hline CD34 & ++ & + \\
\hline VEGF & ++ & + - \\
\hline C-erbB-2 & + & ++ \\
\hline MMP7 & + & ++
\end{tabular}

A semi-quantitative analysis of fluorescence signals in tumour cells was tabulated. Each analysis was based on the observation of at least 20 microscopy fields. anticancer potentials are currently being evaluated in several clinical trials [24]. From an experimental perspective, we plan to develop a large-scale proteomic approach with the aim of identifying additional markers that could also participate in the reduction of growth potential for statin resistant cells in vivo. This type of approach has been recently developed [25] with breast cancer cells in vitro following treatment with lovastatin, but we are not aware of any study that would have analyzed the proteome of cells selected for their resistance to statins. Interestingly, no overlap between our results and those from this analysis was observed. Although this may in part be due to the difference in cell types (breast $v s$ stomach), we surmise that the situations short-term treatment with lovastatin or selection of lovastatin-resistant cells - may not be comparable at all. Future experiments should shed new light on this question.

\section{Conclusion}

This study showed that adaptation to the continuous presence of statins in vitro led to a growth phenotype that was inherited and largely maintained in tumours formed in Nude mice. Hence, growth was reduced in 
statin-adapted tumour cells while showing a higher degree of differentiation and a restricted ability to undergo neo-angiogenesis. The elevation in the levels of pro-caspase-3, pro-caspase-7 and Bax in L50 tumours suggested that they might be more sensitive to anticancer treatments than HGT-1 tumours, since they expressed a higher pool of pro-apoptotic molecules, presumably prone to drug-induced activation. Moreover, that the level of cyclin B1 was lower in L50 tumours suggests that they might be less aggressive and, possibly, more responsive to chemotherapy, a hypothesis that we plan to test in the future. As a model with these HGT-1 and L50 cells, it can be proposed that cancer cells that would appear in individuals undergoing statin therapy would be less likely to develop into tumours. Such effects could account, in part, for the lower incidence of several types of cancers in humans treated by statins for several years, as has been suggested in several retrospective studies $[3,4]$. Future trials could help evaluate this hypothesis through the analysis of markers in tumours from naïve or statin-treated subjects.

\section{Acknowledgements and funding}

We wish to thank Dr C. Laboisse (Université de Nantes, Faculté de Médecine de Nantes, EA Biometadys, Cedex Nantes, France) for his gift of HGT-1 cells. This work was supported by the INSERM, the IFR 148 ScInBioS, the Cancéropôle Grand Ouest, the Ligue régionale contre le Cancer, the FEDER (Fonds Européen de Développement Régional) funds [grant number PRESAGE 9511]; the Brittany Region [project number XCOR 5012838]; the CRITT (Centre Régional d'Innovation et de Transfert de Technologie dans le domaine de la Santé) Santé Bretagne [project number CASAC 2935]; the University of Brest (institutional university grant); the Medical Faculty of the University Hospital of Brest (Interface contract to Laurent Corcos) and the ANIPATH laboratory of the Faculty of Medicine Laënnec (Lyon). Julie Follet was supported by a fellowship from the Brittany region (Allocation de Recherche Doctorale).

\section{Author details}

${ }^{1}$ INSERM U613-ECLA and IFR148-ScInBioS, Université Européenne de Bretagne, Université de Bretagne Occidentale, Faculté de médecine, 22 avenue Camille Desmoulins, 29200 Brest, France. ${ }^{2}$ INSERM U865, Faculté de Médecine RTH Laennec, 7 rue Guillaume Paradin, 69372 Lyon cedex 08, France. ${ }^{3}$ C.Ris Pharma, Parc Technopolitain - Atalante Saint-Malo, 35400 Saint Malo, France.

\section{Authors' contributions}

JF, BS and CLJC performed the cell culture, western blotting and RNA analyses; LR and DG performed the immunohistochemistry analyses; $V H$ and PA performed the mouse analyses; CLC and LC designed the experiments, analyzed the data and wrote the article.

\section{Competing interests}

The authors declare that they have no competing interests.

Received: 17 January 2011 Accepted: 22 November 2011 Published: 22 November 2011

\section{References}

1. Istvan ES, Deisenhofer J: Structural mechanism for statin inhibition of HMG-CoA reductase. Science 2001, 292:1160-1164.
2. Endo A: The discovery and development of HMG-CoA reductase inhibitors. J Lipid Res 1992, 33:1569-1582.

3. Demierre MF, Higgins PD, Gruber SB, Hawk E, Lippman SM: Statins and cancer prevention. Nat Rev Cancer 2005, 5:930-942.

4. Katz MS: Therapy insight: Potential of statins for cancer chemoprevention and therapy. Nat Clin Pract Oncol 2005, 2:82-89.

5. Bjerre LM, LeLorier J: Do statins cause cancer? A meta-analysis of large randomized clinical trials. Am J Med 2001, 110:716-723.

6. Burkhardt R, Kenny EE, Lowe JK, Birkeland A, Josowitz R, Noel M, Salit J, Maller JB, Pe'er I, Daly MJ, et al: Common SNPs in HMGCR in micronesians and whites associated with LDL-cholesterol levels affect alternative splicing of exon13. Arterioscler Thromb Vasc Biol 2008, 28:2078-2084.

7. Hindler K, Cleeland CS, Rivera E, Collard CD: The role of statins in cancer therapy. Oncologist 2006, 11:306-315.

8. Jakobisiak M, Golab J: Potential antitumor effects of statins (Review). Int J Oncol 2003, 23:1055-1069.

9. Fritz G, Kaina B: Rho GTPases: promising cellular targets for novel anticancer drugs. Curr Cancer Drug Targets 2006, 6:1-14.

10. Satoh $K$, Nakai T, Ichihara K: Influence of 3-hydroxy-3-methylglutaryl coenzyme $A$ reductase inhibitors on mitochondrial respiration in rat liver during ischemia. Eur J Pharmacol 1994, 270:365-369.

11. Gibot L, Follet J, Metges JP, Auvray P, Simon B, Corcos L, Le Jossic-Corcos C: Human caspase 7 is positively controlled by SREBP-1 and SREBP-2. Biochem J 2009, 420:473-483.

12. Logette E, Le Jossic-Corcos C, Masson D, Solier S, Sequeira-Legrand A Dugail I, Lemaire-Ewing S, Desoche L, Solary E, Corcos L: Caspase-2, a novel lipid sensor under the control of sterol regulatory element binding protein 2. Mol Cell Biol 2005, 25:9621-9631.

13. Laboisse CL, Augeron C, Couturier-Turpin MH, Gespach C, Cheret AM, Potet F: Characterization of a newly established human gastric cancer cell line HGT-1 bearing histamine H2-receptors. Cancer Res 1982, 42:1541-1548.

14. Bissery MC, Chabot GG: History and new development of screening and evaluation methods of anticancer drugs used in vivo and in vitro. Bull Cancer 1991, 78:587-602.

15. Nejjari M, Anderson W, Pourreyron C, Jacquier MF, Scoazec JY, Remy L: The role of fibroblasts in the modulation of integrin-dependent interactions between the gastric cell line HGT-1 and fibronectin. Int J Cancer 2004, 112:560-569.

16. Livak KJ, Schmittgen TD: Analysis of relative gene expression data using real-time quantitative PCR and the 2(-Delta Delta C(T)) Method. Methods 2001, 25:402-408.

17. Hotz MA, Bosq J, Zbaeren P, Reed J, Schwab G, Krajewski S, Brousset P, Borner MM: Spontaneous apoptosis and the expression of p53 and Bcl-2 family proteins in locally advanced head and neck cancer. Arch Otolaryngol Head Neck Surg 1999, 125:417-422.

18. Tsamandas AC, Kardamakis D, Tsiamalos P, Liava A, Tzelepi V, Vassiliou V, Petsas T, Vagenas K, Zolota V, Scopa CD: The potential role of Bcl-2 expression, apoptosis and cell proliferation (Ki-67 expression) in cases of gastric carcinoma and correlation with classic prognostic factors and patient outcome. Anticancer Res 2009, 29:703-709.

19. Warr MR, Shore GC: Unique biology of Mcl-1: therapeutic opportunities in cancer. Curr Mol Med 2008, 8:138-147.

20. Megha T, Lazzi S, Ferrari F, Vatti R, Howard CM, Cevenini G, Leoncini L, Luzi P, Giordano A, Tosi P: Expression of the G2-M checkpoint regulators cyclin B1 and P34CDC2 in breast cancer: a correlation with cellular kinetics. Anticancer Res 1999, 19:163-169.

21. Kawamoto H, Koizumi H, Uchikoshi T: Expression of the G2-M checkpoint regulators cyclin $\mathrm{B} 1$ and $\mathrm{cdc} 2$ in nonmalignant and malignant human breast lesions: immunocytochemical and quantitative image analyses. Am J Pathol 1997, 150:15-23.

22. Kebebew E, Peng M, Reiff E, Duh QY, Clark OH, McMillan A: Diagnostic and prognostic value of cell-cycle regulatory genes in malignant thyroid neoplasms. World J Surg 2006, 30:767-774.

23. Fukudome $Y$, Yanagihara $K$, Takeichi M, Ito F, Shibamoto S: Characterization of a mutant $\mathrm{E}$-cadherin protein encoded by a mutant gene frequently seen in diffuse-type human gastric carcinoma. Int I Cancer 2000, 88:579-583. 
24. Shah MA, Kelsen DP: Gastric cancer: a primer on the epidemiology and biology of the disease and an overview of the medical management of advanced disease. J Natl Compr Canc Netw 2010, 8:437-447.

25. Klawitter J, Shokati T, Moll V, Christians U: Effects of lovastatin on breast cancer cells: a proteo-metabonomic study. Breast Cancer Res 2010, 12:R16.

Pre-publication history

The pre-publication history for this paper can be accessed here:

http://www.biomedcentral.com/1471-2407/11/491/prepub

doi:10.1186/1471-2407-11-491

Cite this article as: Follet et al: Adaptation to statins restricts human tumour growth in Nude mice. BMC Cancer 2011 11:491.

Submit your next manuscript to BioMed Central and take full advantage of:

- Convenient online submission

- Thorough peer review

- No space constraints or color figure charges

- Immediate publication on acceptance

- Inclusion in PubMed, CAS, Scopus and Google Scholar

- Research which is freely available for redistribution

Submit your manuscript at www.biomedcentral.com/submit 